\title{
Interrelations of perceptual reports of smell, taste and irritance over the near-threshold range, for members of the $\mathbf{N}$-aliphatic monohydric alcohol series'
}

\author{
M. J. MITCHELL AND R. A. M. GREGSON 2 \\ UNIVERSITY OF CANTERBURY, New Zealand
}

\begin{abstract}
Many compounds are psychophysically complex because they stimulate all three chemical senses; smell, taste, and irritance. ${ }^{3}$ Interrelations among these three modalities are reported over the near-threshold range, and comparisons are made for three such compounds; methanol, ethanol, and propanol. Eighteen Ss were tested over 16 sessions each under a range of conditions: a combined task condition that approximated normal drinking, in which thresholds for all three modalities were determined simultaneously, and three conditions, in each of which only one threshold in one modality was determined. Pooled results over Ss gave significant shifts in olfactory thresholds between conditions, whereas changes in gustatory and irritant acuity were less marked. Individual results yielded significant correlations between psychophysical behavior and personality measures. Factor analysis of $S s$ indicated the existence of subgroups of Ss, each typified by different patterns of relative sensitivity over modalities and over alcohols.
\end{abstract}

Sensory interaction has been extensively studied in recent years, particularly by Soviet psychologists (Ryan, 1940; Gilbert, 1941; London, 1954; Pangborn, 1965; Kravkov, 1966), but relatively little attention has been given to interactions involving one or more of the chemical senses (Wilson \& Gregson, 1967).

Gilbert (1941) attempted a summary of the findings of interaction effects, stating that these were a function of the duration and the relative intensity of stimulation in the two modalities involved. However, little of the research which led to his conclusions was conducted in the chemical senses. Individual differences are to be expected, both in sensitivity and the extent to which Ss use various response indicators (Goldiamond, 1958) when one modality may serve as a cue to the presence of another.

The present experiments were conducted to investigate interactions of smell, taste, and irritant perceptual-as opposed to physiological-responses, taken as behavioral indicators of the chemical senses over the near-threshold range, by varying stimulus presentation and response constraint conditions. In a "combined task" condition, Ss were required to report the presence or absence of each of the three types of sensation for each stimulus mixture presented. Three "single task" conditions, one for each phenomenal modality taken separately, were used where Ss reported one dimension only, with the cues from the remaining two modalities being minimized where possible. The experiments were thus not part of a psychophysiological study nor were they in the tradition of classical "inner psychophysics" (Fechner, 1860), but were more concerned with response strategies to complex stimuli furnished by the first three members of the alcohol series: methanol, $\mathrm{CH}_{3} \mathrm{OH}$; ethanol, $\mathrm{C}_{2} \mathrm{H}_{5} \mathrm{OH}$; and 1-propanol, $\mathrm{C}_{3} \mathrm{H}_{7} \mathrm{OH}$. Gibson (1966), in a recent review of taste and smell as channels of information, has questioned the possibility of valid experiments which aim to decompose the sensory gestalten characteristic of the chemical senses. It will be seen that the authors are in complete disagreement with his position, as they understand it.

The lower alcohols are convenient stimuli to employ when studying sensory interactions. They stimulate, at appropriate intensities, smell, taste, and irritance; up to propanol they are miscible with water in all proportions thus affording study of a complete range of concentrations; finally, some insight into the role of chemical structure in determining response may be obtained by examining trends within the series as carbon atoms are added to a basic structure as suggested by Jones \& Jones
(1953). Woskow (1964) compared members of the series in a multidimensional analysis, and Engen (1965) related sensitivity and scaling behavior to chemical structure in the same alcohol series.

\section{Subjects \\ METHOD}

Eighteen Ss, 13 male and five female student volunteers who were naive with reference to the psychophysics involved, were tested over 16 sessions. The sessions were spaced as far as possible, at one-week intervals, and Ss were paid on an ascending scale beginning at $20 \mathrm{c}$ and increasing by $5 \mathrm{c}$ on each successive session to maintain motivation and to avoid dropouts. It was considered preferable to have initially naive $S s$ and expose them all to comparable training procedures rather than take experienced Ss; in this way a more confident interpretation can be given to individual differences. None of the Ss can be regarded as naive after the early experimental sessions.

\section{Apparatus}

Experiments were conducted in the Gustatory Psychophysics laboratory at the University of Canterbury. The Ss were seated individually in a cubicle, at an average ambient temperature of $19.2 \mathrm{degC}$ ( $\mathrm{SD}=0.9 \mathrm{degC}$ ) maintained by bar electric heaters. Gregson (1964) has described the facilities in greater detail. A slide hatchway facing $S$ remained slightly open to provide the only source of light during a block of trials. S's response cues were provided by a signal lighting display mounted inside the cubicle (see Instructions). Responses were made by $\mathrm{S}$ pressing one or more of four Morse keys linked to an Esterline Angus multichannel event recorder, Key $E$ was an error key used if $S$ wished to delete a response he had just made and substitute another. Keys $S, T$, and I were for reporting smell, taste, and irritance, respectively. All keys were labeled with the appropriate letter. The detection of a sensation by $S$ and its corresponding latency were thus recorded.

\section{Sfimuli}

Three primary aliphatic alcohols; methanol, ethanol, and 1-propanol (symbolized as $\mathrm{Me}$, Et, and $\mathrm{Pr}$, respectively, for graphical purposes) were used. They were purchased in the Analytic Reagent Grade (British Drug House specifications) and further purified by repeated distillation to a chromatographic level of purity of one part in 100,000, which was the most rigorous measure of purity readily available. The problem of the dependence of threshold values on stimulus purity arose in this study, but is discussed more fully elsewhere (Mitchell \& Gregson, 1968).

Master solutions were prepared from each of the refined alcohols in geometric dilution series from $50 \%, 25 \%$, and so on down to $0.013 \%$ concentration by volume. These values were selected from a range tried during pilot experiments as discussed below. Tap water was used as diluent, there being an unusually pure local supply of which analyses had been made. Since pilot experiments showed no difference in threshold values between tap water and deionized water (resistance not less than $2 \mathrm{M} \Omega / \mathrm{cm}$ ) this diluent was considered adequate. Master solutions were prepared at least every two days and stored in reagent bottles with air-tight stoppers. After agitation, stimuli were drawn off in $10 \mathrm{ml}$ samples in $50 \mathrm{ml}$ beakers, care being taken to avoid the creation of any volume-intensity effect as reported by Gregson and Paris (1967). The beakers were covered with watch glasses and kept in a Gallenkamp constant temperature bath set at $25 \mathrm{degC}$ for at least 
20 min prior to use. Evaporation was minimized, thus avoiding concentration changes and background odor. The beakers were presented to Ss in trays holding five.

Ethanol was used throughout pilot experiments and training sessions for the main experiment since its relatively slight toxic effects made it most suitable. The toxicity of methanol was guarded against by having Ss drink a solution of $5 \%$ sodium bicarbonate and 5\% D-glucose (Browning, 1965) before and after each session. This prophylactic was taken at all sessions, regardless of the alcohol to be tested, to avoid any response bias that might have otherwise been introduced.

Background air was continuously circulated by fans to minimize airborne vapor. This is necessary for health reasons, in the case of methanol, and for psychophysical reasons (Baker, 1963).

\section{Design of Experiment}

The general plan of the 16 experimental sessions for each $S$ was as follows: Session 1-a training session; Sessions 2 through 4combined task (C1). On each session one only of the three alcohols was used, and the order of use was randomized over the $18 \mathrm{Ss}$; Sessions 5 through 13-single task (C3); on each session one of the nine substance by modality combinations was investigated, and the three alcohols and three modalities within an alcohol were randomized for order over the $18 \mathrm{Ss}$; Sessions 14 through 16-combined task (C2). The arrangement of conditions was as for $\mathrm{C} 1$, but the order in which a given $\mathrm{S}$ encountered the three alcohols was again randomized and not the same in $\mathrm{C} 2$ as in $\mathrm{C} 1$.

In the training session, and in $\mathrm{C} 1$ and $\mathrm{C} 2$, stimuli were presented in a modified ascending series method of limits procedure. Stimuli were presented in ever-increasing concentrations even after $S$ had reported the presence of any one sensation, until the solutions were sufficiently concentrated to elicit all three of smell, taste, and irritant responses. C3 was divided into three sub-conditions, one for each modality (see below). On all runs, false positive responses were checked by requiring the same positive detection response to be made for two adjacent concentrations, and dummy blanks were also introduced for the same purpose.
Data from the training session which was run with ethanol were not used in the analysis presented here. At each of Sessions 2 through 16, five runs up the stimulus series were made, to determine one or three thresholds, whichever was appropriate. At least $1 \mathrm{~min}$ separated the presentation of stimuli and longer periods were used with the more concentrated stimuli, Ss reporting when they were ready to continue.

The lights in the taste cubicle were switched off during each block of trials, but turned on at the end of each run after a threshold determination. Between runs, Ss filled out rating scales, which also provided a period of readaptation.

\section{Pilot experiments}

Preliminary experiments were run, using Ss who did not take part in the main experiments. They were to determine: (a) the stimulus range which was most likely to be sub-threshold for the most sensitive $\mathbf{S}$ and the most detectable modality at one extreme, and supra-threshold for the least sensitive $S$ and the least detectable modality at the upper extreme, (b) the ability of Ss to carry out the tasks, because of their novelty and complexity, and (c) effective means of determining a threshold for each modality whilst minimizing stimulation from other modalities. Irritance posed particular problems in this respect. The final form of instructions to Ss set out below was framed in the light of these checks.

The determination of relatively unimodal thresholds in $\mathrm{C3}$ presented some difficulties. Olfactory thresholds can be obtained without initially stimulating receptors of the other modalities by having Ss sniff gently. Taste thresholds may be obtained with olfactory cues minimized by blocking the nose with cotton wool, although some odorant may reach the olfactory cavity via the back of the throat. This cannot be avoided in unconstrained stimulus presentation. But irritant receptors are not so readily isolated, particularly from taste. It does not seem possible to stimulate oral irritant receptors without simultaneously stimulating taste, unless surgical preparation of Ss is effected. To minimize this problem, stimuli were administered by $E$ via a

\begin{tabular}{|c|c|c|c|c|}
\hline $\begin{array}{l}\text { Time Scale } \\
(\operatorname{secs})\end{array}$ & - & 2 & 6 & $9----$ \\
\hline $\begin{array}{l}\text { Position of } \\
\text { Signal Light }\end{array}$ & 1 & & - & 1 \\
\hline $\begin{array}{l}\text { Subject's } \\
\text { Behaviour }\end{array}$ & & & & \\
\hline $\begin{array}{l}\text { Combined } \\
\text { Task }\end{array}$ & Relaxes & $\begin{array}{l}\text { Removes cover, } \\
\text { raises beaker to } \\
\text { lips. }\end{array}$ & $\begin{array}{l}\text { Takes sample into mouth, } \\
\text { responds. }\end{array}$ & $\begin{array}{l}\text { Spits out, continues } \\
\text { respondigg if desired } \\
\text { rinses, replaces } \\
\text { beaker, relaxes. }\end{array}$ \\
\hline $\begin{array}{l}\text { Taste as } \\
\text { Single Task }\end{array}$ & Relaxes & $\begin{array}{l}\text { Removes cover, } \\
\text { raises beaker to } \\
\text { lips. }\end{array}$ & $\begin{array}{l}\text { Takes sample into mouth, } \\
\text { responds. }\end{array}$ & $\begin{array}{l}\text { Spits out, continues } \\
\text { responding if desired } \\
\text { rinses, replaces } \\
\text { beaker, relaxes. }\end{array}$ \\
\hline $\begin{array}{l}\text { Smell as } \\
\text { Single Task }\end{array}$ & Relaxes & $\begin{array}{l}\text { Removes cover, } \\
\text { raises beaker to } \\
\text { nose. }\end{array}$ & Takes snifr(s), responds. & $\begin{array}{l}\text { Replaces heaker, } \\
\text { relaxes. }\end{array}$ \\
\hline $\begin{array}{l}\text { Irritance } \\
\text { as Single } \\
\text { Task }\end{array}$ & Retaxes & $\begin{array}{l}\text { Places mouth } \\
\text { over nylon tube. }\end{array}$ & $\begin{array}{l}\text { Receiver sample, rolls it } \\
\text { around molth. responds. }\end{array}$ & $\begin{array}{l}\text { Spits out, continues } \\
\text { responding if desired } \\
\text { rinses, relaxes. }\end{array}$ \\
\hline
\end{tabular}

Fig. 1. Time relations between $S$ 's behavior and changes in signal lights. 
hypodermic syringe with a soft nylon tube in place of the needle. This enabled the solution to be trickled onto the inner wall of the S's cheek. This stimulates, initially at least, irritant receptors only. The alternative method, whereby the Ss took the solution into their mouths in the usual way but selectively attended to irritance (which was phenomenologically reported as "tickling" or "burning" by many Ss) gave comparable threshold values, but the hypodermic method was adopted for C3 because latency of response was thus slightly decreased.

A modified "equilibrium sniffer" suggested by Turk (1964) was adopted for the measurement of smell thresholds as single tasks. After use, the crucibles were washed and stood in a dessicator containing self-indicating silica-gel (dessicant) and activated charcoal (deodorant).

Subjects with colds were not used, and all Ss were required to sit before an electrical heater for $10 \mathrm{~min}$ warming their faces prior to testing. It was found that cold weather lowered sensitivity in all modalities. Ss were asked to refrain from eating or smoking $30 \mathrm{~min}$ before coming to sessions, and following Baker (1964) Ss washed their hands before testing.

A marked difference was found to separate thresholds on the first and subsequent trials in a session. Thresholds were invariably lower on the first run, and it is suggested that the first trial produces a detection threshold, whilst on subsequent runs recognition thresholds are reported. This effect held for taste and smell but not for irritance. To furnish as many comparable data as possible, all runs were turned into recognition thresholds by having Ss sample a very concentrated sample of the alcohol to be used on that day, at the start of each session. All the above features were incorporated into the main design.

\section{Main experiments}

Figure 1 summarizes the instructions controlling S's movements during each of the conditions; written instructions in much greater detail were provided for Ss before and during testing.

At the training session (1) three training stimuli (sucrose solution, diluted orange juice, and sherry with citric acid) were administered to familiarize Ss with the procedure, but not with the subsequent stimuli. A $25 \%$ ethanol solution was presented to $\mathrm{S}$ with the warning that this was the substance to be tasted in the session. Water was presented and $S$ told to regard it as tasteless. The strong alcohol sample and the water were presented on all Sessions 1 through 16 with the same instructions. Figure 1 summarizes the procedure and S's movements during each task.

\section{Self-rating data}

During intervals between testing, Ss rated the ease or difficulty of the experimental task, checked stimulus properties on an attribute rating scale, and completed the Eysenck Personality Inventory (Form A), at the end of Session 16.

\section{RESULTS}

The ease of judgment ratings showed no between-task differences and were therefore not further analyzed. It is important to note, however, that Ss did not report finding the combined task too difficult to perform. Very few "Erase" responses were made (only seven out of over 30,000 taken) so these were ignored. Latencies were not treated in any detail as they proved generally uninformative, though irritant responses were typically of longer latency than those of the other two modalities on C3 sessions. On $\mathrm{C} 1$ and $\mathrm{C} 2$ sessions they were longer for those Ss who seemed to assess each modality independently. Other Ss on $\mathrm{C} 1$ and $\mathrm{C} 2$ tasks tended to withold responses in any modality until the stimulus had been generally assessed, so that eventually responses in all three modalities would be made simultaneously.

For convenience of statistical manipulation, threshold levels are hereafter given in log units (L) of the per cent concentration scale where

$$
\mathrm{L}=\log _{2}(\mathrm{vol} \text { alcohol/total vol })+14 \text {. }
$$

For a $50 \%$ concentration $\mathrm{L}=13$, for $25 \% \mathrm{~L}=12$ and so on (Beebe-Center \& Waddell, 1948; Dove, 1953). The pooled threshold values for each condition given in Table 1 are each based on 18 independent means from the Ss, and each individual mean is based on five determinations. Thresholds were defined in terms of mean .5 detection probability points, as is usual.

The values from the $18 \mathrm{Ss}$ by 27 conditions matrix of threshold determinations were subjected to a 3 by 3 by 3 analysis of variance with repeated observations on all variables and 18 observations per cell. All of the main effect terms were significant: the thresholds for smell, taste, and irritance were significantly different; the three alcohols were detectable at different concentrations; and the conditions of measurement by response constraint ( $\mathrm{C} 1, \mathrm{C} 2$, or $\mathrm{C} 3$ ) influenced thresholds significantly. Relevant $F$ values are: between $\mathrm{Ss}, \mathrm{F}=6.96, \mathrm{df}=17 / 468, \mathrm{p}<$ 0.001 ; within Ss main effects: Modalities, $\mathrm{F}=84.21$, df $=2 / 34, \mathrm{p}$ $<0.001$; Alcohols, $\mathrm{F}=149.67, \mathrm{df}=2 / 34, \mathrm{p}<0.001$; Conditions, $\mathrm{F}=22.05, \mathrm{df}=2 / 34, \mathrm{p}<0.001 ;$ Modalities by Alcohols, $\mathrm{F}=$ 15.92 , $\mathrm{df}=4 / 68, \mathrm{p}<0.001 ;$ Modalities by Conditions, $\mathrm{F}=48.54$, df $=4 / 68, p<0.001 ;$ Modalities by Alcohols by Conditions, $F=$ $2.10, \mathrm{df}=8 / 136, \mathrm{p}<0.05$

It is seen that for smell, the threshold for methanol was intermediate between those of ethanol (the highest) and propanol (the lowest), and this relationship held under all three conditions used. Admittedly $\mathrm{C} 1$ and $\mathrm{C} 2$ are expected to differ only as the consequence of the interpolated sessions in which Ss served under $\mathrm{C} 3$ conditions. The small differences between $\mathrm{C} 1$ and $\mathrm{C} 2$ point to an absence of learning effects and a reliability of the values, thus emphasizing the contrast, for smell, between $\mathrm{Cl}$ and $\mathrm{C} 2$ on the one hand, and $\mathrm{C} 3$ on the other. High test-retest reliability similarly obtains for the other modalities.

Table 1

Pooled Thresholds, Inter-quartile Ranges and their Residuals

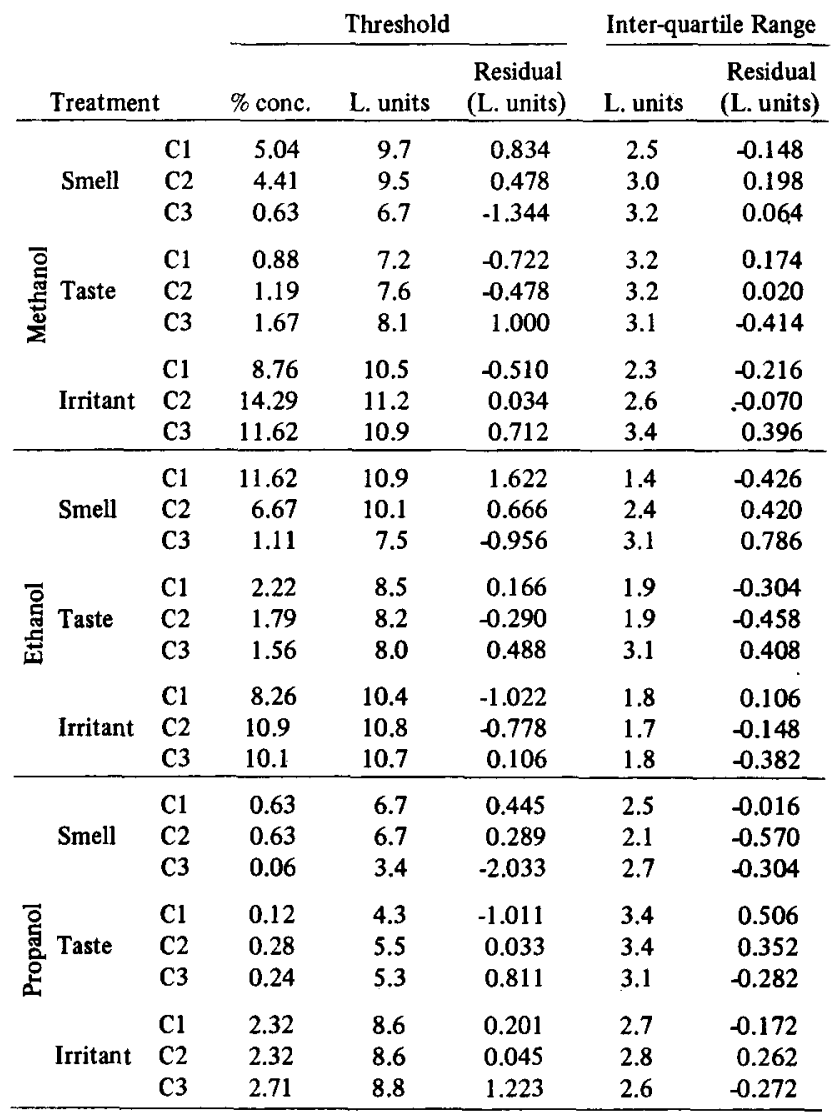


For the other two modalities the thresholds of methanol and ethanol were hardly distinguishable, but again propanol had clearly the lowest threshold, for all conditions.

Overall, for these three alcohols, taste and irritant response thresholds appeared to be relatively unaffected by the conditions under which they were elicited, but a marked effect showed itself in the case of smell. Thresholds in this tatter modality were lower than those for taste under the single task conditions, and higher than those for taste under the combined task.

The significant interaction terms in the analysis of variance indicate that the alcohols varied in the extent to which they differed as stimuli over modalities and over conditions. The difference between ethanol and propanol, for example, was greatest on smell and least on irritance. The Modalities by Conditions significant interaction emphasizes the difference in the extent to which smell is influenced by conditions, as opposed to the less obvious influences on the other two modalities.

Examination of the analysis of variance residuals of the thresholds under each condition (as set out in Table 1) confirmed the reliability and homoscedasticity of observations (Cox, 1958).

\section{Between-subject differences}

It became apparent during earlier sessions that Ss differed in their patterns of response from treatment to treatment. While this is not unexpected, the present design which replicated treatments three times (once for each alcohol) revealed that differences in patterns of response were not all random day-to-day fluctuations; some Ss consistently responded in one fashion, other Ss consistently responded in another. Attempts to reveal subgroups of Ss were, therefore, made, first, by intercorrelating psychophysical and personality variables, and second, by factor analytic treatment of the between-subject correlation matrix.

Three psychophysical variables were chosen for intercorrelation with Eysenck Personality Inventory variables of Extraversion,
Neuroticism, and a Lie score. These psychophysical variables were given the names "Variance" (a within-session variance score for each S), "Anticipatory Positive" score (for what are known elsewhere as "false positive" responses) and a "Taste Threshold Shift" score [for the difference between single and combined task taste thresholds and chosen since previous studies have revealed the susceptibility of this modality to intermodal effects (Gregson \& Paris, 1967; Wilson \& Gregson, 1967)] ."

Intercorrelations between the chosen indices are set out in Table 2 with values significant beyond the .05 level marked by an asterisk. The Neuroticism-Lie Score relation has previously been noted by Eysenck (1964), and the Lie Score was the only personality variable which correlated significantly with the psychophysical variables of variance and Taste Threshold Shift.

No validation studies of the Eysenck Lie score have been noted. This scale was adapted from the similar scale of the MMPI, and this is believed to measure Social Desirability (Hathaway \& McKinley, 1951). The significant correlations suggest that Ss who gave "socially desirable" responses are less variable, and are less influenced by intermodal effects. In the present context, "socially desirable" responses may arise mainly from subjective perception of the E's aims, and with the properties of the stimuli being somewhat suppressed in the decision situation. Subjects often volunteered information which supports this assertion.

The between-subject correlation matrix ( 18 by 18 with each $r$ based on 27 pairs of mean threshold values) was treated by Principal Components analysis with the unrotated components taking up $78.32 \%, 4.89 \%, 3.49 \%, 2.39 \%$, and $2.56 \%$ of the variance. The very large first component accounts for the general homogeneity of the data and gives some indication of the extent to which mean results are a convenient basis for population predictions. However, Varimax rotation redistributed the variance so that, $38.79 \%, 34.78 \%$, and $26.43 \%$ of the rotated variance is taken up by the first three factors, and these give some basis for an account of individual differences. ${ }^{4}$

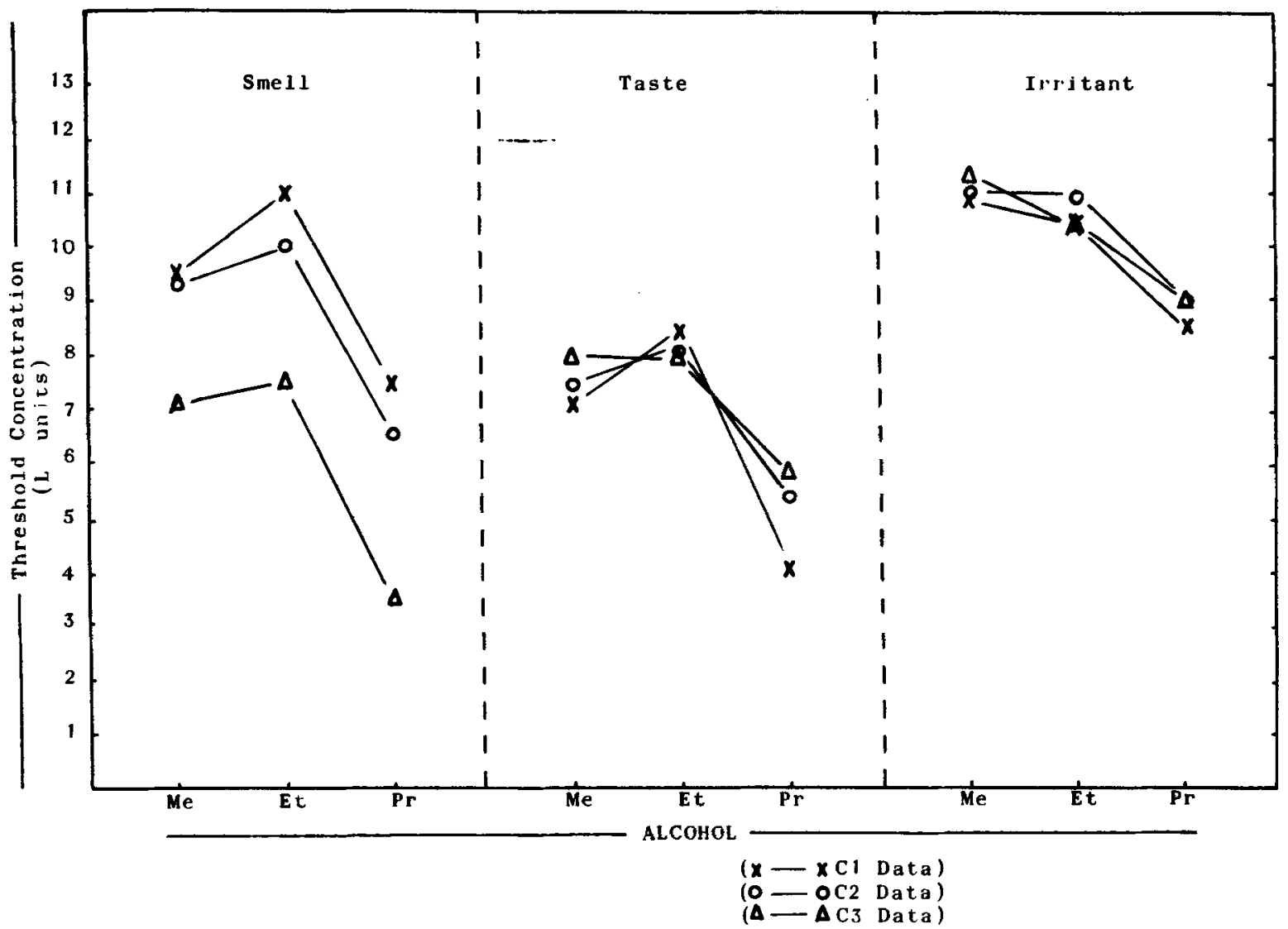

Fig. 2. Pooled Thresholds. 
Tablè 2

Intercorrelations of Personality and Psychophysical Variables

\begin{tabular}{lcccccc} 
& Ext. & Neu. & Lie & Var. & A.P. & T.T.S. \\
\hline Ext. & - & -.333 & -.026 & .287 & .007 & .087 \\
Neu. & & - & $-.484^{*}$ & -.140 & .016 & .156 \\
Lie & & & - & $-.490^{*}$ & -.223 & $-.523^{*}$ \\
Var. & & & & - & $.552^{*}$ & .051 \\
A.P. & & & & & - & -.136 \\
T.T.S. & & & & & & -
\end{tabular}

${ }^{*} p<0.05(d f=16)$

Ext. $=$ Extraversion

Neu. $=$ Neuroticism

Lie - Lie Score

Var. $=$ Variance

A.P. $=$ Anticipatory Positive

T.T.S. $=$ Taste Threshold Shift

Factor $\mathbf{I}_{\mathbf{S}}$, called "alcohol ordering," revealed two main subgroups of Ss which differed in their relative sensitivity to the three alcohols. Group la (with loading $>0.6$ ) ordered the alcohols as methanol, ethanol, and propanol in increasing sensitivity in all modalities, confirming Engen's (1965) findings for olfaction. Group $1 \mathrm{~b}$ (with loading $<0.4$ ) ordered the alcohols as ethanol, methanol, and propanol in increasing sensitivity. Factor $\mathrm{II}_{\mathrm{s}}$ appears to be a "modalities differences" factor, in that Ss with high $\mathrm{Il}_{\mathrm{s}}$ loadings had high irritance thresholds, relative to the other modalities, whereas $\mathrm{Ss}$ with low $\mathbf{I I}_{\mathbf{s}}$ loadings had irritance thresholds scarcely different from taste and smell. Introspective reports indicate that hedonic tone might be invoked as some sort of explanation for these differences in response pattern; some Ss with low irritance thresholds reported disliking high concentrations and possibly give these lower irritance thresholds through some form of avoidance strategy. III $_{\mathrm{s}}$ appeared stimulus bound, like $\mathrm{I}_{\mathrm{s}}$; the magnitude of $\mathrm{III}_{\mathrm{s}}$ loadings parallels S's sensitivity to propanol, relative to the other alcohols, within a given modality.

The first unrotated factor of the between-treatments Principal Components analysis (of the 27 by 27 matrix with each $r$ based on 18 pairs of observations) took up $53.07 \%$ of the variance, compared with $78.32 \%$ accounted for by $\mathrm{I}_{\mathrm{S}}$ unrotated. Ss can be interchanged more readily than treatments for purposes of prediction. Varimax rotation again redistributes the variance so that only $28.30 \%$ of the rotated variance is taken up by factor $\mathrm{I}_{\mathrm{t}}$. The first six factors of the treatments analysis were included in the rotation.

Factor It was labeled "irritance sensitivity," its highest loadings being exclusively confined to this modality. Similarly, $\mathrm{II}_{\mathrm{t}}$ was labeled "taste sensitivity," although the pattern of high loadings was less specific to this modality. III $\mathrm{t}$ was tentatively labeled a " $\mathrm{C} 2$ condition" factor, but no reason can be offered for the difference between this and $\mathrm{Cl}$ loadings $(\mathrm{Cl}$ being an identical treatment to $\mathrm{C} 2$ ). $\mathrm{IV}_{\mathrm{t}}$ has larger loadings on propanol treatments and was labeled "propanol stimulation." $V_{t}$ could possibly be smell sensitivity, while $\mathrm{VI}_{\mathrm{t}}$ was not identified.

The general picture given by the components analyses facilitates the classification of Ss into groups with characteristic response patterns and emphasizes again the heterogeneity of responses to complex taste stimuli which has been commented on elsewhere (Gregson, 1964; Gregson \& McCowen, 1963). The factors of the stimulus conditions do not entirely match the treatments' set up, and the relative amounts of variance taken up make any theory relating response to simpler features of molecular structure distinctly implausible.

\section{DISCUSSION AND CONCLUSIONS}

The $C_{1}$ and $C_{2}$ tasks employed in this study are so complex that they may constitute a precedent for the psychophysics of the chemical senses. It has been shown that consistent results, with high between-subject agreement are possible under these conditions, but that results are not predictable from simpler unimodal tasks.

For the three lowest members of the alcohol series, measured as a series of single threshold tasks, olfaction is the most sensitive chemical sense, and irritance the least sensitive. This finding is in agreement with the qualitative results of Parker and Stabler (1913) although their quantitative results for ethanol are suspect on the grounds of stimulus purity (Mitchell \& Gregson, 1968) and not therefore a strict precedent against which to compare present findings.

Smell thresholds shift from the combined task condition downwards to the more usual single task condition. In the combined task condition they may even be above taste thresholds. Why this shift takes place, in the face of the relative stability of the thresholds of the other two modalities, is not clear. It could be due either to an intersensory effect at the response end of the total psychophysical process, or to some artifact of shifts of attention in Ss, consequent on differences in method used under the conditions compared, or to both.

Threshold values based on pooled data can be seriously misleading as an indication of intersensory effects. Pooled data shows no difference between single and combined task taste thresholds. However, examination of the records of individual Ss reveals within-subject consistencies and between-subject consistent differences; some Ss have lower taste thresholds under the combined task condition, whilst others have consistently higher thresholds, for all three alcohols. It appears that the amount of information available to Ss, or the amount they are instructed to use, has variable effects on different $S s$ in this context, even allowing for the familiar semantic confusions between smell and taste which naive Ss commonly display in gustatory experiments.

To determine the precise extent to which taste thresholds are likely to be shifted by the collateral presence or absence of odor stimuli, more precise stimulus control is needed. This experiment has served to show a marked and unpredicted effect which may be maximal under the relatively unconstrained stimulus presentation procedures of the combined task, which was deliberately chosen for its face validity in simulating the circumstances of normal perception.

Irritant thresholds are not influenced by manipulations of the levels of the other components in the stimuli, although it should be noted that the elimination of taste cues is impossible using the present method of single task presentation of stimuli. Therefore irritant thresholds on both the combined and single tasks may be depressed through the operation of avoidance response strategies. Taste stimulation can elicit irritant responses at stimulus concentrations below "true irritant threshold." Introspective reports indicate that persons most likely to respond in this fashion have the greatest dislike for the stimuli.

Engen's (1965) observation that olfactory thresholds decrease with an increasing number of carbon atoms in the alcohol chain cannot be generalized to include methanol, the lowest member of the series. Engen did not test this substance. The relative thresholds of methanol and ethanol varied from $O$ to $O$, some following Engen's direct relation between chemical structure and sensitivity, while others showed greater sensitivity to methanol than to ethanol. In all cases, propanol thresholds were lowest in all modalities, supporting Engen's findings. The unique chemical properties of the lowest member of any homologous series are often ignored when extrapolations are made from experiments on the higher members. These lowest members should be studied in their own right where possible, although considerations of toxicity preclude many such compounds from detailed study (e.g., formaldehyde, formic acid, etc.). Hedonic aspects of the different members of a homologous series may also be important; Ss who showed greater sensitivity to methanol than ethanol often reported that methanol was the most unpleasant of the three alcohols used.

Taste threshold shift and variability of response correlated significantly with the Lie Scale of the Eysenck Personality Inventory. This finding can be subsumed under the rubric of "socially desirable" responses. Gregson and Wilson (1967) report a significant relation between Extraversion (Maudsley Personality Inventory) and similar psychophysical behavior. The present study failed to confirm their finding.

Factor analyses have clarified between-subject and between- 
treatment differences, revealed only at a gross level by analyses of variance.

Gibson (1966, Chapter VIII) has pointed out that taste is simuitaneously tactile, thermal, and haptic, usually odorous and frequently hedonic. He suggests these are inseparable; that taste is a multisensory gestalt and its components have no roles and no measurable perceptual correlates in isolation. "All inputs are concomitant since the receptors are made to covary by the activity of the mouth." This theory hangs on the meaning of "concomitant," but it is certainly the case that Ss can selectively attend to one component of a taste mixture (Gregson, 1968) or to one dimension of a multisensory gustatory stimulus, and there is also evidence (Pangborn \& Trabue, 1962) that such variables as viscosity and thermal conductivity can be altered and yet leave taste perception unchanged. The evidence of the present study is taken to imply that Ss can attend to individual sensory dimensions of stimulation from the alcohol series taken as examples of potentially trimodal stimuli; though the results of such attention vary with the response constraints imposed in a way which has to be determined empirically. Gibson is right in observing that gustatory perception is not unimodal, and not a good instance of a psychophysical isomorphism between stimulus and response dimensions. But this does not mean that the psychophysics of the modality is an inextricable tangle. Just as the metrics of visual form can yield to an appropriate multivariate analysis (Michels \& Zusne, 1965) so those of taste can be disentangled, even though the resultant components do not correspond to some phenomenologically simple sensory qualities, which Gibson postulates, and then asserts introspection cannot reveal.

The present study has shown that experimentation involving simultaneous multidimensional stimulation of chemical senses can yield meaningful and consistent data which do not require recourse to physiological considerations for explanation. The approach of classical "inner psychophysics" also imposes unnecessary constraints upon this type of experimentation. Response data need not be tied to detailed descriptions or speculations (Gander et al, 1964) of receptor function. Data are only meaningful when the constraints on both stimuli and responses are fully explicit. Some applied scientists and technologists (Baker, 1963; Bruvold \& Gaffey, 1965) have laid considerable emphasis on threshold values as invariant measures of the relative potency of stimuli. It is held here that such emphases are unsound and rest on a fundamental misconception about the nature of the judgment processes mediating complex psychophysical relations.

\section{REFERENCES}

BAKER, R. A. Threshold odors of organic chemicals. J. Amer. Water Works Assn., 1963, 55, 913-916.

BEEBE-CENTER, J. G., \& WADDELL, D. A general psychological scale of taste. J. Psychol, 1948, 26, 517-524.

BROWNING, E. Toxicity and metabolism of industrial solvents. New York: Elsevier, 1965.

BRUVOLD, W. H., \& GAFFEY, W. R. Subjective intensity of mineral taste in water. J. exp. Psychol., 1965, 69, 369-374.

COX, D. R. Planning of experiments. New York: John Wiley, 1958.

DOVE, W. F. A universal gustometric scale in D-units. Food Res., 1953, 18, 427-453.

ENGEN, T. Psychophysical analysis of the odor intensity of homologous alcohols. J. exp. Psychol, 1965, 70,611-616.

EYSENCK, H. J., \& EYSENCK, S. B. G. Eysenck Personality Inventory. Bedford: Sidney Press, 1964.

FECHNER, G. T. Elemente der Psychophysik. Leipzig: Breitkopf und Hartel, 1860.

IANDER, J. E., GRIFFIN, F., \& FISCHER, R. A multiple site chemo- teceptor model. Arch int. Pharmocodyn. 1964, 151, 540-551.

GIBSON, J. J. The senses considered as perceptual systems. New York: Houghton Mifflin, 1966.

GILBERT, G. M. Intersensory facilitation and inhibition. J. gen. Psychol, $1941,24,381407$.

GOLDIAMOND, I. Indicators of perception. Psychol Bull., 1958, 55, 373-411.

GREGSON, R. A. M. Modification of perceived relative intensities of acid tastes by ambient illumination changes. Austral J. Psychol, 1964, 16, 190-199.

GREGSON, R. A. M. Simulating perceived similarities between taste mixtures with mutually interacting components. Brit. J. math. statist. Psychol, 21, 1968 , in press.

GREGSON, R. A. M., \& McCOWEN, P. J. The relative perception of weak sucrose-citric acid mixtures.J. Food Sci., 1963, 28, 371-378.

GREGSON, R. A. M., \& PARIS, G. L. Intensity-volume interaction effects in gustatory perception. Percept. \& Psychophys, 1967, 2, 483-487.

HATHAWAY, S. R., \& McKINLEY, J. C. Minnesota Multiphasic Personality Inventory (Manual). New York: The Psychological Corporation, 1951.

JONES, F. N., \& JONES, M. H. Modern theories of olfaction: a critical review. J. Psychol, 1953, 36, 207-241.

KRAVKOV, S. V. Interaction of the sense organs. Psychological research in the U.S.S.R., 1. Moscow: Progress Publishers, 1966. Pp. 218-266.

LONDON, I. D. Research in sensory interaction in the Soviet Union. Psychol Bulh, 1954, 51, 531-568.

MICHELS, K. M., \& ZUSNE, N. Metrics of visual form. Psychol Bull., 1965, $63,74-86$.

MITCHELL, M. J., \& GREGSON, R. A. M. Stimulus specificity and thresholds of the chemical senses, in press.

PANGBORN, R. M. The interaction of the senses. (A review of selected literature.) Material compiled for the Americal Standards Institute, 1965. Personal communication.

PANGBORN, R. M., \& TRABUE, I. M. Taste interrelationships, V; sucrose, sodium chloride, and citric acid in lima bean puree. J. Food Sci, 1964, 29, 233-240.

PARKER, G. H., \& STABLER, E. M. On certain distinctions between taste and smell. Amer. J. Physiol, 1913, 32, 230-240.

RYAN, T. Interrelations of the sensory systems. Asychol Bull, 1940, 37, 659-698.

TURK, A. Approaches to sensory odor measurement. Ann. N. Y. Acad. Sci, $1964,16,465467$.

WILSON, G. D., \& GREGSON, R. A. M. Effects of illumination on perceived intensity of acid tastes. Austral J. Psychol, 1967, 19, 69-73.

WOSKOW, M. H. Multidimensional scaling of odors. Unpublished doctoral dissertation. University of California, Los Angeles, 1967.

\section{NOTES}

1. This research was supported by grants from the University Grants Committee of New Zealand made to R. A. M. Gregson, and the experiments were conducted by $M$. J. Mitchell in partial fulfillment of M.Sc. degree regulations at the University of Canterbury.

2. Address: Psychology and Sociology Department, University of Canterbury, Christchurch, New Zealand.

3. The terms "irritance" and "irritant" refer to the Common Chemical Sense. This avoids confusion with the more general term "Chemical Senses" used when referring collectively to smell, taste, and the common chemical sense. 4. Full details of the data and their treatments are available from the authors and includes: (1) methods of deriving psychophysical variables, and their magnitude for each $S$, (2) thresholds for all 18 Ss under all 27 treatments, (3) between-subject and between-treatment correlation matrices, (4) tables of rotated and unrotated factor loadings.

(Accepted for publication February 21, 1968.) 